\title{
Global status of the robotic thoracic surgery
}

\author{
Ricardo Mingarini Terra, Pedro Henrique Cunha Leite, Alberto Jorge Monteiro Dela Vega
}

Thoracic Surgery Division, Heart Institute (InCor) do Hospital das Clínicas da Faculdade de Medicina, Universidade de São Paulo, São Paulo, Brazil Contributions: (I) Conception and design: All authors; (II) Administrative support: All authors; (III) Provision of study materials or patients: All authors; (IV) Collection and assembly of data: All authors; (V) Data analysis and interpretation: All authors; (VI) Manuscript writing: All authors; (VII) Final approval of manuscript: All authors.

Correspondence to: Ricardo Mingarini Terra, PhD, MD. Thoracic Surgery Division, Heart Institute (InCor) do Hospital das Clínicas da Faculdade de Medicina, Universidade de São Paulo, São Paulo, Brazil. Email: rmterra@uol.com.br.

\begin{abstract}
Robotics has taken its place in thoracic surgery since the end of the 20th century. Since then, it has been developed worldwide with many different applications, such as the treatment of mediastinal tumors and lung cancer. Although, the contradictory results comparing this new technology to other minimally invasive techniques may raise some skepticism, the high quality of the instrument and images provided by the robot brings a whole new perspective for the thoracic surgeon, since the robotic platform can ally the ease of movement obtained with open technique with the advantages of the minimally invasive surgery. When it comes to the implementation of a robotic program the costs of RATS are an important issue. However, it is necessary to take into account not only the cost of the robotic platform itself but also the maintenance expenses, disposable tools, and training programs. Nevertheless, the cost of the robotic surgery is expected to decrease in the coming years and like the instrumentation, virtual reality will see improvements. Many different countries around the world have contributed with original articles for the development of the robotic thoracic surgery and in this paper, we aim at describing the global status of the robotic thoracic surgery.
\end{abstract}

Keywords: Robotic surgical procedures; minimally invasive surgical procedures; thoracic surgery; video-assisted

Submitted Dec 28, 2019. Accepted for publication Oct 21, 2020.

doi: $10.21037 /$ jtd-19-3271

View this article at: http://dx.doi.org/10.21037/jtd-19-3271

\section{Introduction}

Minimally invasive techniques in thoracic surgery have been developed since the decade of 1990 . Initially the use was more frequent for pleural procedures like decortication or pleural biopsies; however, its use for more complex procedures became more frequent in the decade of 2000 with the dissemination of video-assisted thoracic surgery (VATS) for the treatment of lung cancer, especially the VATS lobectomy (1-4). Since then, the technique has widespread and rich literature regarding the comparison between the approaches has emerged. Some studies have shown that the VATS Lobectomy is safe, with oncological results equivalent to open technique and even with advantages in terms of postoperative morbidity (2-4). The main concern of the thoracic surgeons to adopt the VATS for lung resections and larger procedures is the paucity of movements provided by the VATS instrument. In this context came on the scene the robotic-assisted thoracic surgery (RATS) aiming to provide enhanced gestures and movements but still keeping the minimally invasive aspects of VATS.

Up to now, the only accessible robotic system is the da Vinci Surgical System (Intuitive Surgical Inc., Sunnyvale, CA, USA) whose models are composed of 3 different units namely patient cart, imaging cart, and console. The patient cart encompasses the 4 arms that have contact with the patient through the specifically designed instrument, the imaging cart is where the light source, energy devices, and $\mathrm{CO}_{2}$ source are placed and also where the main data is processed. The camera is fixed in one of the arms and is 
also controlled by the surgeon. A 3D high definition camera provides a magnified image with impressive quality. The console is the part where the surgeon commands the robotic arms using the hands and the feet (5).

The first studies that dealt with the theme were descriptive and depicted the feasibility, technical aspects, and safety of the technique either for lung resections or thymoma resections and thymectomy (6-8). Park et al. exhibited good morbidity and intraoperative mortality rates with fair long-term oncological outcomes (9).

The contrast between VATS and RATS is in constant discussion in the surgeon's community at present. Most of the ones who have tried the robotic approach advocated that a more precise dissection is achieved especially in mediastinal lymphadenectomy and other approaches to the mediastinum. On the other hand, arguments are raised against the new technique considering the higher costs for the implementation of a robotic surgery program and the expenses with the articulated tools.

Comparative studies between RATS and VATS have shown contradictory clinical results. Kent et al. using a large database, compared the results of robotic lobectomies or segmentectomies to the same surgeries performed by thoracotomy or VATS and found statistically significant reductions in mortality, length of stay and overall complications rates in the comparison with open technique but found no difference compared to VATS (10). Huang et al. in a retrospective analysis of 166 patients, compared VATS and robotic approaches for anatomical lung resections performed by the same surgeon and found a higher rate of prolonged air leak and length of stay in the robotic group (11). Li et al. in a large retrospective study comparing VATS and Robotic for lobectomies in earlystage lung cancer, using propensity scores match, found better results for RATS regarding the number of lymph nodes retrieved, chest tube duration, volume of chest tube drainage in the first post-operative day and length of stay (12). A meta-analysis published by Liang et al. found lower 30-day mortality and shorter length of stay in the RATS group (13).

Despite the good results of the robotic approach in clinical practice, when it comes to the implementation of a robotic program, the costs are always an important issue. It is necessary to take into account not only the cost of the robot itself but also the maintenance expenses, disposable tools, and training programs. Some studies have addressed this issue and RATS is frequently related to higher costs when compared to VATS $(12,14,15)$. However, some authors argue that the mastering of the technique leads to better clinical results, shorter length of stay and lower nursing costs, thereby causing a reduction of costs (16).

In the following paragraphs we will describe through the eyes of the current literature, how is the global status of robotic thoracic surgery approaching the papers published by continent.

\section{Robotic thoracic surgery across the world}

Robotic systems have been used in thoracic surgery since the late 1990s, firstly for Cardiac surgery. However, the da Vinci robotic system that is the most used system by now was approved by the US Food and Drug Administration (FDA) in 2000 and the first thoracic procedure was reported in 2001. From then on, the robotic technique in all surgical specialties has widespread and it also happened in thoracic surgery.

\section{The United States and Canada}

Since the beginning of the robotic thoracic surgery in 2001, the United States has experienced a gradual expansion of minimally invasive surgery. Data from the U.S. Department of Health \& Human Services shows an increased in the adoption of the robotic technique. In a period of 4 years, between 2009 and 2013, the robot-assisted lobectomy raised from $1 \%$ to $11 \%$ of all lobectomies while VATS remained with $33 \%$ and the percentage of open-lobectomies dropped from $66 \%$ to $46 \%(17,18)$. It is estimated that, in 2015 , approximately $15 \%$ of the lobectomies were performed with a robotic system in the US (17).

The United States has contributed substantially to the development and standardization of robotic thoracic surgery. Dylewski et al. published a large series of lung resection describing the technique. The surgery was performed with a total endoscopic robotic video-assisted approach that uses three robotic arms. A pneumothorax is induced with an injection of $\mathrm{CO}_{2}$ to facilitate the tissues dissection and to help the lung collapse. In this series, the surgical specimen was removed through the transdiaphragmatic subcostal access (19).

In 2017, The American Association of Thoracic Surgeons published a proposed definition and nomenclature for robotic thoracic surgery. The consensus statement defines what is robotic thoracic operation. The nomenclature system gathers information about the type of resection, the necessity of an assist port, the number of ports used and if 
the procedure met the definition of robotic-assisted. The objective was to enable future adequate comparison between studies (20).

In Canada, robotic surgery was introduced in October 2011. The first Canadian series was published with 167 cases with outcomes comparable to other series in the literature (21).

\section{Latin America}

Although promising, robotic surgery is still in its early days in Latin America. The first procedures were performed in 2006 and until recently there were only two active centers, one in São Paulo, Brazil and one in Bogotá, Colombia. Nonetheless, there is a growing interest in the technique. Academic centers started to publish their initial experience. In Brazil, the first robotic program was settled in 2015 at Universidade de São Paulo in the context of a Prospective Randomized trial comparing VATS and RATS whose preliminary results (10 cases) were published in 2016 (22). Since then, the Brazilian experience has steadily increased. In a series recently published by Terra et al., 250 cases were reported including not only lung resection but also mediastinal tumors resections and diaphragmatic plication $(23,24)$. In 2019, Buitrago and Restrepo published the second series of RATS in Latin America, with 14 cases of pulmonary resections showing comparable perioperative results to other reports (25).

The lack of publications makes it particularly difficult to analyze in more depth the current status of thoracic robotic surgery in Latin America.

\section{Europe}

The start of a "thoracic robotic era" became reality in Europe at the beginning of the 21 st century and the development of this technique has been through the participation of many European institutions. The pioneering center was the University of Pisa, which performed the first robot-assisted anatomic lung resection in 2001 (26). The same group in 2008 published a series of 107 cases of robotic lobectomy with good surgical outcomes and early postoperative recovery (27).

In 2010, Veronesi et al. published a series of 54 robotic lobectomies for the treatment of early-stage lung cancer. It was used a propensity score match to select 54 patients submitted to open lobectomy for comparison. The study found a shorter length of stay in the robotic group when compared to the open surgery group. Besides that, there was no difference in the number of lymph nodes dissected between the two techniques neither in the number of complications (28).

Regarding mediastinal disorders, Institutions from several European countries reported promising results. Marulli et al. published in 2013, a series of 100 robotic thymectomies for the treatment of Myasthenia Gravis. It this study, it was observed that the technique was safe and achieved neurological benefit in $87.5 \%$ of cases (29). The same group published two different European multiinstitutional series that analyzed thymectomy for thymoma showing the feasibility and safety of the technique $(8,30)$.

European thoracic surgeons have fostered robotic thoracic surgery and created substantial literature and data about the method. More recently, the European Society of Chest Surgeons started to create events helping the widespread of the method. One of these workshops occurred in 2016 in Milan, Italy and gathered experts from around the world. It was discussed surgical technical details, new systems improvements, costs issues, and future studies. Currently, there is a randomized clinical trial in progress that aims to compare robotic and VATS approaches in the treatment of early-stage lung cancer (31).

\section{Asia}

Robotic thoracic surgery in Asia is expanding gradually, and the largest series of cases are concentrated in Japan, Korea, and China. The main Asian centers for thoracic surgery are not limited to conventional procedures such as standard lobectomy or resection of mediastinal tumors, there are some case reports of more complex procedures such as robotic sleeve lobectomy for the treatment of lung cancer (32,33).

In Japan, RATS is also increasing, mainly after 2018 when it came to be funded by the national health insurance system. Nakamura et al. published in 2014 a series of 112 cases including lung cancers and a variety of mediastinal tumors with a low rate of post-operative complications (34).

In Korea, Ahn et al. in their initial experience of 87 patients published in 2019, robotic lobectomy for lung cancer had a longer surgical duration and higher blood loss in comparison to VATS. Although RATS have provided a better lymphadenectomy, there was no difference between the two techniques in concerning nodal upstaging (35).

Zhao et al. from China published in 2010 their first experience with robotic thoracic surgery having the first 
patient operated on in 2009 (36). Huang et al. published a series of 48 patients (11 lobectomies, 37 mediastinal tumor resections) (7). Nowadays, China has been recognized as a growing robotic thoracic center with a high volume of patients.

Most recently, India published the first experience of the use of robotic surgery in inflammatory and infective disease in a third world country. They have shown the use of RATS for different procedures, including decortication, segmentectomy, and pneumonectomy and used yoga and other integrated medicine to help postoperative recovery (37).

\section{Perspectives}

The robotic system has been gradually improving and extending its applications. The development of this technology is welcome and for sure will be responsible for achieving even better surgical outcomes.

Despite, single-port technology has already been used, it is still not a reality for thoracic surgery. More recently, a thoracic uniportal dispositive is in development and it is expected to be commercialized in a few years (38).

New technologies have evolved concurrently with robotics. One of them is the use of fluorescence. In the latest years, it was created a new optical system and incorporated into the da Vinci platform. This device enables the fluorescence-guided surgery using intravenous administration of the indocyanine green (ICG). It has become a faithful tool to identify the intersegmental plane in anatomic lung segmentectomies $(17,39)$.

Another field of research aims to better identify pulmonary nodules and noble structures like blood vessels and nerves that are invisible in the surgeon's range of view. The prospect is to be able to use a system that acquired an intraoperative $3 \mathrm{D}$ image and create a superposed figure with the real anatomic structures in augmented reality (31).

To date, new robots are being developed by some companies such as Medtronic and by the association of Johnson \& Johnson with Google. Possibly the development of other robotic platforms, can reduce the costs related to this technology and improve its widespread (17).

\section{Conclusions}

Over the past few years, the robot-assisted approach for surgical treatment of thoracic diseases has been disseminated worldwide. Different centers in the world have used the technology for procedures with a broad range of complexity.

\section{Acknowledgments}

Funding: None.

\section{Footnote}

Provenance and Peer Review: This article was commissioned by the Guest Editor (Ghulam Abbas) for the series "Robotic Thoracic Surgery" published in Fournal of Thoracic Disease. The article has undergone external peer review.

Conflicts of Interest: All authors have completed the ICMJE uniform disclosure form (available at: http://dx.doi. org/10.21037/jtd-19-3271). The series "Robotic Thoracic Surgery" was commissioned by the editorial office without any funding or sponsorship. The authors have no other conflicts of interest to declare.

Ethical Statement: The authors are accountable for all aspects of the work in ensuring that questions related to the accuracy or integrity of any part of the work are appropriately investigated and resolved.

Open Access Statement: This is an Open Access article distributed in accordance with the Creative Commons Attribution-NonCommercial-NoDerivs 4.0 International License (CC BY-NC-ND 4.0), which permits the noncommercial replication and distribution of the article with the strict proviso that no changes or edits are made and the original work is properly cited (including links to both the formal publication through the relevant DOI and the license). See: https://creativecommons.org/licenses/by-nc-nd/4.0/.

\section{References}

1. Terra RM, Waisberg DR, Almeida JL, et al. Does videothoracoscopy improve clinical outcomes when implemented as part of a pleural empyema treatment algorithm?. Clinics (Sao Paulo) 2012;67:557-64.

2. McKenna RJ, Houck W, Fuller CB. Video-assisted thoracic surgery lobectomy: Experience with 1,100 cases. Ann Thorac Surg 2006;81:421-5; discussion 425-6.

3. Tsukazan MTR, Terra RM, Vigo Á, et al. Video-assisted thoracoscopic surgery yields better outcomes than thoracotomy for anatomical lung resection in Brazil: A 
propensity score-matching analysis using the Brazilian Society of Thoracic Surgery database. Eur J Cardiothorac Surg 2018;53:993-8.

4. Falcoz PE, Puyraveau M, Thomas PA, et al. Videoassisted thoracoscopic surgery versus open lobectomy for primary non-small-cell lung cancer: A propensitymatched analysis of outcome from the European Society of Thoracic Surgeon database. Eur J Cardiothorac Surg 2016;49:602-9.

5. Wei B, Cerfolio RJ. Robotic Lobectomy and Segmentectomy: Technical Details and Results. Surg Clin North Am 2017;97:771-82.

6. Ashton RC, Connery CP, Swistel DG, et al. Robot-assisted lobectomy. J Thorac Cardiovasc Surg 2003;126:292-3.

7. Huang J, Luo Q, Tan Q, et al. Initial experience of robotassisted thoracoscopic surgery in China. Int J Med Robot 2014;10:404-9.

8. Marulli G, Rea F, Melfi F, et al. Robot-aided thoracoscopic thymectomy for early-stage thymoma: A multicenter European study. J Thorac Cardiovasc Surg 2012;144:1125-30.

9. Park BJ, Melfi F, Mussi A, et al. Robotic lobectomy for non-small cell lung cancer (NSCLC): Longterm oncologic results. J Thorac Cardiovasc Surg 2012;143:383-9.

10. Kent M, Wang T, Whyte R, et al. Open, video-assisted thoracic surgery, and robotic lobectomy: Review of a national database. Ann Thorac Surg 2014;97:236-42; discussion 242-4.

11. Huang L, Shen Y, Onaitis M. Comparative study of anatomic lung resection by robotic vs. Video-assisted thoracoscopic surgery. J Thorac Dis 2019;11:1243-50.

12. Li JT, Liu PY, Huang J, et al. Perioperative outcomes of radical lobectomies using roboticassisted thoracoscopic technique vs. video-assisted thoracoscopic technique: Retrospective study of 1,075 consecutive p-stage I non-small cell lung cancer cases. J Thorac Dis 2019;11:882-91.

13. Liang H, Liang $W$, Zhao L, et al. Robotic versus videoassisted lobectomy/segmentectomy for lung cancer: a meta-analysis. Ann Surg 2018;268:254-9.

14. Deen SA, Wilson JL, Wilshire CL, et al. Defining the cost of care for lobectomy and segmentectomy: a comparison of open, video-assisted thoracoscopic, and robotic approaches. Ann Thorac Surg 2014;97:1000-7.

15. Park BJ, Flores RM. Cost comparison of robotic, videoassisted thoracic surgery and thoracotomy approaches to pulmonary lobectomy. Thorac Surg Clin 2008;18:297-
300, vii.

16. Dylewski MR, Lazzaro RS. Robotics - The answer to the Achilles' heel of VATS pulmonary resection. Chin J Cancer Res 2012;24:259-60.

17. Veronesi G, Novellis P, Voulaz E, et al. Robot-assisted surgery for lung cancer: State of the art and perspectives. Lung Cancer 2016;101:28-34.

18. Novellis P, Bottoni E, Voulaz E, et al. Robotic surgery, video-assisted thoracic surgery, and open surgery for early stage lung cancer: comparison of costs and outcomes at a single institute. J Thorac Dis 2018;10:790-8.

19. Dylewski MR, Ohaeto AC, Pereira JF. Pulmonary Resection Using a Total Endoscopic Robotic VideoAssisted Approach. Semin Thorac Cardiovasc Surg 2011;23:36-42.

20. Cerfolio R, Louie BE, Farivar AS, et al. Consensus statement on definitions and nomenclature for robotic thoracic surgery. J Thorac Cardiovasc Surg 2017;154:1065-9.

21. Fahim C, Hanna W, Waddell T, et al. Robotic-Assisted thoracoscopic surgery for lung resection: The first Canadian series. Can J Surg 2017;60:260-5.

22. Terra RM, de Araujo P, Lauricella LL, et al. Robotic pulmonary lobectomy for lung cancer treatment: program implementation and initial experience. J Bras Pneumol 2016;42:185-90.

23. Terra RM. Thymic minimally invasive surgery: state of the art across the world: Central-South America. J Vis Surg 2017;3:124.

24. Terra RM, Haddad R, de Campos JRM, et al. Building a Large Robotic Thoracic Surgery Program in an Emerging Country: Experience in Brazil. World J Surg 2019;43:2920-6.

25. Buitrago MR, Restrepo J. Robot-assisted thoracic surgery in Colombia : a multi-institutional initial experience. Ann Cardiothorac Surg 2019;8:233-40.

26. Melfi FMA, Menconi GF, Mariani AM, et al. Early experience with robotic technology for thoracoscopic surgery. Eur J Cardiothorac Surg 2002;21:864-8.

27. Melfi FMA, Mussi A. Robotically assisted lobectomy: learning curve and complications. Thorac Surg Clin 2008;18:289-95, vi-vii.

28. Veronesi G, Galetta D, Maisonneuve P, et al. Four-arm robotic lobectomy for the treatment of early-stage lung cancer. J Thorac Cardiovasc Surg 2010;140:19-25.

29. Marulli G, Schiavon M, Perissinotto E, et al. Surgical and neurologic outcomes after robotic thymectomy in 100 consecutive patients with myasthenia gravis. J Thorac 
Cardiovasc Surg 2013;145:730 -5; discussion 735-6.

30. Marulli G, Comacchio GM, Rea F, et al. Multiinstitutional European experience of robotic thymectomy for thymoma. Ann Cardiothorac Surg 2016;5:18-25.

31. Veronesi G, Cerfolio R, Cingolani R, et al. Report on first international workshop on robotic surgery in thoracic oncology. Front Oncol 2016;6:214.

32. Jo MS, Kim DY, Jeong JY, et al. Robotic sleeve lobectomy with four arms for lung cancer centrally located in the right lower lobe: A case report. J Cardiothorac Surg 2017;12:108.

33. Zhao Y, Jiao W, Ren X, et al. Left lower lobe sleeve lobectomy for lung cancer using the Da Vinci surgical system. J Cardiothorac Surg 2016;11:59.

34. Nakamura H, Suda T, Ikeda N, et al. Initial results of robot-assisted thoracoscopic surgery in Japan. Gen Thorac Cardiovasc Surg 2014;62:720-5.

Cite this article as: Terra RM, Leite PHC, Dela Vega AJM. Global status of the robotic thoracic surgery. J Thorac Dis 2021;13(10):6123-6128. doi: 10.21037/jtd-19-3271
35. Ahn S, Jeong JY, Kim HW, et al. Robotic lobectomy for lung cancer: initial experience of a single institution in Korea. Ann Cardiothorac Surg 2019;8:226-32.

36. Zhao X, Qian L, Lin H, et al. Robot-assisted lobectomy for non-small cell lung cancer in china: initial experience and techniques. J Thorac Dis 2010;2:26-8.

37. Khan AZ, Khanna S, Agarwal N, et al. Robotic thoracic surgery in inflammatory and infective diseases. Ann Cardiothorac Surg 2019;8:241-9.

38. Konstantinidis KM, Hirides P, Hirides S, et al. Cholecystectomy using a novel Single-Site $®$ robotic platform: early experience from 45 consecutive cases. Surg Endosc 2012;26:2687-94.

39. Pardolesi A, Veronesi G, Solli P, et al. Use of indocyanine green to facilitate intersegmental plane identification during robotic anatomic segmentectomy. J Thorac Cardiovasc Surg 2014;148:737-8. 